\title{
Hearing Red: \\ Aurality and Performance in a Film by Simon Gush
}

\author{
BRETT PYPER \\ Wits School of Arts, University of the Witwatersrand
}

Focusing on the film that accompanies Simon Gush's installation Red, this article positions itself within the 'ambient humanities' and explores sound as its primary mode of inquiry. I consider how sound constitutes not just the soundtrack but also, at particular moments, becomes the subject of the film itself. I believe these moments are worth attending to because, empirically speaking, they render audible some aspects of history that might otherwise literally be overlooked. Taking my cue from a striking aural performance recounted in the film, I consider possible archaeologies of insurrectionary noise in South Africa and beyond. Beyond the empirical, I am interested in theorising not only about but also with sound, and reflecting on how doing so with respect to history might be productive. I thus tease out thinking about sound in history, sound with history, sounding history and the like, in the process asking what aesthetics can do for the work of history. Drawing on ideas advanced recently by John Mowitt (2015), I consider how the notions of echo and resonance illustrate the kinds of alternative epistemological perspectives that attention to sound might enable for historiography. In the conclusion, I tie these back to the foregrounding of performance - particularly performance with a strong aural dimension - in the constitution of social and public memory.

The film that accompanies Simon Gush's installation $\operatorname{Red}^{1}$ begins, in the absence of a visual image for its first several seconds, with the sound of a voice. Intimately recorded close-up so that tone and register are foregrounded, it is a male voice remembering: 'I think on the 25th of May. Must have been a Wednesday.'

The act of remembering is conveyed (or is it constituted?) in the rising inflection of the speaker's voice as he reaches back into a past re-membered (reassembled), his pitch peaking as he recalls the specific day, the 'twenty-fifth', before settling back to its initial level, his certainty that it was 'May' underlined with emphatic staccato articulation.

For the duration of the long sequence with which the film opens, memory is constituted in a vocal register (the title shows after ten minutes, at which point the

1 Red is a multi-media art installation by the South African conceptual artist and photographer Simon Gush that was first shown at the Goethe Institute in Johannesburg from March to May 2014. The film on which I focus here, made with James Cairns, was a central part of the installation. It tells the story of the events of 1990 through interviews with representatives from management and labour. Edited with evocative video footage of contemporary East London, it is marked by an almost photographic stillness. For more about the project and online access to the film itself, see http://www.simongush.net/red/. 
soundtrack switches to traffic noise and visuals of the entrance to the Mercedes-Benz plant in East London, South Africa, c. 2013). In the measured cadences of Xhosainflected English, we hear the deliberately paced recollections of Thembalethu Fikizolo, a shop steward at the time of the momentous transition from the overt hostility and labour anomie of the late 1980s to the iridescent moment that produced the Mercedes for Madiba. As the recounted narrative unfolds, this emerges as a pinnacle moment in a longer social drama where the forces of labour and capital engage in ongoing wars of position, sometimes within their respective constituencies, with the crisis-ridden if transitioning South African state ever in the background. The striking 'red' moment on which Gush dwells marks a break, however fleetingly amidst the noise of history, into song.

In terms of its content, the film Red largely comprises oral history testimony, interspersed with video images that approximate to still photography in dwelling visually on places at and around the factory in contemporary East London. The narrative is recounted to varying degrees by six workers who appear still to be in the employ of Mercedes at the time of filming. ${ }^{2}$ Three interlocutors present the perspectives of the then management, all of whom appear to have either retired or moved on to other assignments. Over the film's 82-minute duration, the recollections are intercut so as to provide complementary and in some instances competing accounts of what emerge as cardinal moments in the speakers' respective professional lives. The narrative begins with the virtual paralysis of the Mercedes plant in the late 1980s in the context of heightened struggle against apartheid. The moment of Nelson Mandela's release in 1990 sparks an initiative on the part of workers to build him a car. This amounts, in a moment of rare consensus, to a performance of the possible beyond alienated labour, which Fikizolo, invoking a sonic metaphor, refers to as being on the same wavelength, across the board. 3 The last half-hour of the film deals with the on-the-ground challenges, despite the 'Madiba moment, ${ }^{4}$ of establishing a new labour relations regime in the post-apartheid era, particularly a move towards collective bargaining and (in Fikizolo's account) countervailing ambitions among certain worker representatives. This led to a so-called 'wildcat' sleep-in strike that shut the plant down for nine weeks and ultimately led to the dismissal of over five hundred workers. Nonetheless, the closing slide of the film asserts the stability and international recognition that was afforded this once dysfunctional plant after 1994 until the strike of 2013, which seems emblematic of the receding of the Madiba moment in what turned out to be the year of Mandela's death.

2 It is unclear whether the footage dates from before or after the strike of 2013 , the first to have occurred at the plant since the events recounted in the film.

3 The reference is made at $51^{\prime} 50$ " into the film.

4 This phrase was invoked, particularly during Mandela's presidency, to describe the magical effect that his presence at an event seemed to precipitate, especially to spur the national rugby and soccer teams to unlikely victories. 
This article takes its cue from recent writing referred to under the rubric of the 'ambient humanities ${ }^{5}$ and explores sound as its primary mode of inquiry. I recognise - particularly in the context of studying a soundtrack designed to accompany as strongly visual a medium as a film - that this is a reading (or, better, a hearing) that presses against the material grain of its subject. But as I have begun to emphasise in my brief account of the film above, I am struck by how sound constitutes not just the soundtrack per se, but also, at particular moments, becomes the content or subject of the film itself. ${ }^{6}$ I believe these moments are worth attending to because, empirically speaking, they render audible some aspects of history that might otherwise literally be overlooked. Beyond the empirical, I am interested in thinking or theorising not only about but also with sound, and reflecting on how doing so with respect to history might be productive. Gush's film has thus prompted me to tease out thinking sound in history, sound with history, sounding history and the like, in the process asking what aesthetics can do for the work of history. ${ }^{7}$

In the pages that follow, taking my cue from a striking aural performance recounted in the film, I consider possible archaeologies of insurrectionary noise in South Africa and beyond. Following Mowitt, ${ }^{8}$ I go on to consider how the notions of echo and resonance illustrate the kinds of alternative epistemological perspectives that attention to sound might enable for historiography. In the conclusion, I tie these back to the foregrounding of performance - particularly performance with a strong aural dimension - in the constitution of social and public memory.

\section{Towards an Archaeology of 'Shrill Whistling'}

The soundtrack of Red is largely ambient, understated and, apart from the sounds of the narrators' voices, non-diegetic, ${ }^{9}$ underscoring the stillness of the visual material. Under the introductory narrative and later interviews, relatively placid sounds of the sea, of ship signals, of wind, rustling leaves or, more stridently, of traffic and trains envelop, underscore or punctuate the narrative. There is no attempt to illustrate the recounted events sonically; instead, the soundtrack contributes a contrapuntal sequence of contemplative impressions, inviting a reflection on, if not immersion in, the place of these events. Neither is there any concerted attempt to provide what Murray Schafer conceived as 'soundmarks': emblematic sounds that are distinctive

The specific allusion to the ambient humanities is to the subtitle of John Mowitt's recent monograph Sounds (Oakland: University of California Press, 2015), which usefully surveys a wide field of relevant writing apart from offering resonant new ways of thinking about knowing as sound, and with and through sound. Mowitt's participation in the 'Red Assembly' workshop introduced me to him in person and his writing has inspired this article on several levels. In Sounds, Mowitt takes his theoretical coordinates largely from 20th-century post-Saussurean semiotic and post-Freudian psychoanalytic traditions of critical theory, which he brings to bear in a sequence of literary and cinematic readings. The ambient humanities would necessarily include the 'sensory turn' in historiography, represented inter alia by James H. Johnson's Listening in Paris: A Cultural History (Berkeley: University of California Press, 1996), Bruce Smith's The Acoustic World of Early Modern England: Attending to the O-Factor (Chicago: University of Chicago Press, 1999), Jonathan Sterne's The Audible Past: Cultural Origins of Sound Reproduction (Durham: Duke University Press, 2003) and Richard Cullen Rath's How Early America Sounded (Ithaca NY: Cornell University Press, 2005). See the special issue of the journal Radical History Review, 121, January 2015, titled 'Sound Politics: Critically Listening to the Past'. Thanks to an anonymous reviewer for drawing out this point.

Thanks to a second anonymous reviewer for emphasising this.

Mowitt, Sounds.

Diegetic sound is present in the action of a film or play (like the voices of characters and the noises made by their actions), while non-diegetic sound is added from elsewhere and would not be audible to the cast in a given scene (like a musical soundtrack). 
of particular places. ${ }^{10}$ The ambient sounds are, rather, generic in character and appear to have been incidental to the process of visually documenting places around the Mercedes-Benz plant in East London at the time of filming. The soundtrack thus stands in an anachronistic relationship to what is told; both the visual and the sonic material presented in the film date from the time of the oral history being narrated, rather than attempting to quote or reconstruct an archive that is contemporaneous with the recounted events. ${ }^{11}$

Nonetheless, the narrative in the film is striking for the evidence it offers of the considerable extent to which, in the late 1980s at least, resistance to the intersecting forces of capital and apartheid was overtly performative. This goes well beyond generalised modes of demonstration that occurred across South Africa like the singing of struggle songs and public performances of a figurative war dance like the toyi-toyi, ${ }^{12}$ accompanied by black power salutes or even, in the case of the events recounted in the film, the ceremonious draping of Mandela's vehicle with the flag of the African National Congress (ANC) ${ }^{13}$ Workers at the Mercedes-Benz plant also appear to have elaborated a range of resistant, if not openly combative, performance modes with notable dramaturgic, choreographic and sonic dimensions. ${ }^{14}$ Given my interests in the latter, to my mind one the most striking impressions in the film is aural. It emerges not in the soundtrack but among the recollections of one of its participants. Charles Nupen, who mediated several disputes in the mid to late 1980s, describes a visit to the plant at the time:

I can recall going with a couple of members of my team to just get a sense of what it was like in that plant, to get a kind of feel of the relationships that existed at the time. And I can remember being taken in to the plant by the chief executive, Christoph Köpke, and there was, like, this shrill whistling that started that just pervaded the plant as we walked through, you know. And it was a, it was a kind of demonstration, of people's antagonism towards senior management. And that's they way they expressed. I mean, they didn't stop, put down tools, they didn't stop working, but they just demonstrated in that way their antagonism and their displeasure with his presence in the plant.

10 'The term soundmark is derived from landmark and refers to a community sound which is unique or possesses qualities that make it specially regarded or noticed by the people in that community. Once a soundmark has been identified, it deserves to be protected, for soundmarks make the acoustic life of the community unique.' R.M. Schafer, The Tuning of the World (New York: Alfred Knopf, 1977).

11 A fragment of such an archive exists and has been used, apparently by the Mercedes-Benz company itself, to produce a short video titled Labour of Love that presents an entirely consensual account of the events of 1990. It includes contemporaneous footage of workers labouring on Mandela's car, dancing, singing, presenting black power salutes and deploying the ANC flag, and accompanying the vehicle through various stages of production to its being driven from the plant. Available on Youtube at https://www.youtube.com/watch?v=ZLtYr3d0wvs, accessed 8 November 2015.

12 The toyi-toyi is a stamping war dance associated with popular resistance in southern Africa of the late apartheid period that was reportedly learnt from the Zimbabwe People's Revolutionary Army forces in the context of anticolonial struggle in that neighbouring country.

13 The display of the ANC's flag, visible in the Labour of Love footage, had been banned for decades until only weeks before the footage included in the video was filmed.

14 Examples of performances of resistance recounted in the film that are not examined here include the wearing of wooden 'dummy' guns at work and, Gush's installation invites us to consider, the appropriation of materials used to produce car seats and other parts to make improvised beds during the strike of 1994. 
This anecdote is compelling not only for the evidence it offers of what may on the surface have been an idiosyncratic mode of sonic resistance (more about that later), but also because it contains evidence of how this performance was read/heard by participants positioned on the side of management. It is presented not as the shrill whistle of surprise or warning, but explicitly of antagonism and displeasure directed at a particular audience. It leaves one with the visceral impression of members of the management and their consultants running a sonic gauntlet as they enter into a workspace over which they have but nominal authority.

The efficacy of sound to constitute a collectivity, and for this to be experienced unambiguously at somatic and emotive levels, in this instance directs opprobrium at those who, regardless of their formal power, are excluded from the performance; in fact, they become its disempowered objects. To risk stating the obvious, this is pertinently not a utilitarian injunction to 'whistle while you work'. ${ }^{15}$ Aurally rendering the industrial plant ungovernable even as the routines of production are ostensibly maintained, one imagines the whistling creating a situation where instructions cannot be given or taken as a wall of sound isolates the team of officials and inspectors and renders them impotent, certainly for the duration of the performance. ${ }^{16}$

Parallels might be heard between the shrill whistling recounted in Gush's film and various vernacular archives, particularly those that relate to histories of public shaming and insurrectionary noise. These have been documented at least as far back as medieval Europe and are associated with various pan-European cultural practices glossed in English as 'rough music'. These were transported to North America, where they acquired their own forms and vocabularies alongside practices that signalled resistance and rebellion in the Afro-diasporic cultural circuits wrought by the transatlantic slave trade. Such performative archives and repertoires ${ }^{17}$ thus have local and global dimensions, each with their own elusive aural histories, which in the case of southern Africa have tended to be mute in the colonial record. Nonetheless, to those who lived through the transition from apartheid in South Africa, the indefinably distinctive whistling of demonstrators and marshals that accompanied public marches, rallies and funerals throughout the 1980s reverberates with a sound world that included the heaving pulse of the toyi-toyi and also a characteristically South African proclivity for demonstrating through song. Without necessarily citing them, local performances of the sort attributed to the workers in East London in the late 1980s echo or resonate with these longer sonic repertoires of resistance (I return to the work these sonic verbs do below), and Gush's film leads one to reflect on how one might unravel these layered, potentially intersecting, performative modes in historical terms.

15 The reference is to Frank Churchill's song 'Whistle While You Work', with lyrics by Larry Morey, for the 1937 animated Disney film Snow White and the Seven Dwarfs.

16 During discussion at the 'Red Assembly' workshop, Simon Gush reported that he had also heard recollections that workers sometimes used to bang tools with the same effect as the whistling recounted here.

17 I borrow this felicitous phrase, for somewhat different purposes, from Diana Taylor's The Archive and the Repertoire: Performing Cultural Memory in the Americas (Durham: Duke University Press, 2003). 
The shrill whistling mentioned by Charles Nupen in Red thus recalls various customs, documented in rural regions but also in the metropoles of colonial powers from the earliest modern times, where rough music has been chronicled. The celebrated social historian E.P. Thompson offers a definitive account in an article first published in 1972, later expanded as a chapter in his study of the culture of working people in England in the eighteenth century, Customs in Common. ${ }^{18}$ In Thompson's definition:

'Rough music' is the term which has been generally used in England since the end of the seventeenth century to denote a rude cacophony, with or without more elaborate ritual, which usually directed mockery or hostility against individuals who offended against certain community norms. It appears to correspond, on the whole, to charivari in France, to the Italian scampanate, and to several German customs - haberfeld-treiben, thierjagen and katzenmusik. There is, indeed, a family of ritual forms here, which is European-wide, and of great antiquity, but the degree of kinship within this family is open to enquiry. ${ }^{19}$

By designating the relationship between this common feature of vernacular European culture and the shrill whistling at the Mercedes-Benz plant in East London, South Africa in the late twentieth century as a resonance, I am able to avoid speculation as to whether a causal relationship might exist between them. While such practices have an uncanny propensity for being distributed globally without any formal effort (much like children's games), my intention is not to discover the provenance of the acts of resistance that took place at the factory, which could have entailed any combination of repetition and improvisation. But the wide range of public performances referred to as rough music throws into relief aspects of the social dynamics at play in the events at the plant as recalled by Nupen that helps one to note both correspondences and divergences.

The parallels between rough music and the shrill whistling recounted in the film are strongest in their effect as rituals of public shaming. To the extent that the whistling communicated the hostility that Nupen reports feeling at the time, it perhaps more closely approximates to the closely related sibilant act of hissing (a nonverbal mode of communication traced to communicating aggression or defensiveness, even among several animal species), or its more mellifluent cousin hushing, than the modes of whistling that have tended to have cheerful connotations in Western popular culture. ${ }^{20}$ There appears to have been no ambiguity in the message received by management from the workers who whistled shrilly at them when they approached. But in the flagrant 'voicing' of animosity in the face of management while nominally doing their work, this kind of performance on the part of workers in East London

18 E.P. Thompson, Customs in Common (London: Merlin, 1991). I am indebted to Mowitt's monograph Percussion: Drumming, Beating, Striking (Durham NC and London: Duke University Press, 2002) for directing me to these sources.

19 Thompson, Customs in Common, 467.

Less cheerful associations of whistling with madness and Fascism in twentieth-century film are considered by Mowitt in Sounds. 
seems to have taken on aspects of cultural struggle that challenged, rather than upheld, the social and political status quo, and to that extent it departs from its parallels with rough music.

For E.P. Thompson, rough music served as a mode of popular justice or community policing practised among the plebeian classes - most often serving to uphold patriarchal, heteronormative sexual mores - though it could also be invoked to counter domestic violence. And while it signalled 'the total publicity of disgrace, ${ }^{21}$ Thompson holds that ' $[e] v e n$ when rough music was expressive of the most absolute community hostility, and its intention was to ostracise or drive out an offender, the ritual element may be seen as channelling and controlling this hostility.22 In sum, rough music served a socialising and disciplinary function, not a revolutionary one.

John Mowitt (a cultural theorist who, happily for my purposes, also had a career as a professional musician) drew attention some time ago to the sense in which a 'strike' involves a sonic image, specifically a percussive one. ${ }^{23}$ The import of this insight goes beyond the literal sense of the strike serving as a collective mobilisation of the working classes to 'strike back' at the abuses of capital. Mowitt also invites reflection (to offer my own paraphrase that riffs a little on his exposition) on the extent to which striking entails the deliberate, tactical interruption of the routines and thus the rhythms of industrial labour. It is precisely this deliberate and tactical dimension of the strike that leads Mowitt to foreground why activists in the history of trade unionism have been at pains to distinguish strikes from the kinds of rough music discussed by Thompson. Citing Wilfred Harris Crook's 1931 study of the history of the general strike, Mowitt draws out the following:

Crook shows how strike organizers frowned on the forms of 'spontaneous' uprising represented by rough music. In his mind, such uprisings derive precisely from those carnivalesque practices whose politics have recently been rehabilitated by the likes of Bakhtin, Peter Stallybrass, and Allon White. As such, they are to be sacrificed to the requirements of an effective strike, which, in order to gain public support and realize its political purpose, must be above all discipline. ${ }^{24}$

Crook's account illustrates a tension that has long been debated by scholars of actual carnivals as opposed to those who theorise about them in cultural terms. Like Thompson on rough music, scholars with a more empirical agenda point out that the apparent spontaneity ascribed to the carnivalesque often overlooks the highly structured, socialising dimensions of these events in practice. ${ }^{25}$ Black workers whistling shrilly at white employers to their face in late apartheid South Africa could




thus equally be read as a disciplined mode of coordinated resistance on the factory floor (but not yet a formal strike, which was to follow later), though it may conjure up images of insurrectionary noise that have a dynamic, unstable character. Again, viewed this way, the purpose of the whistling is not to maintain dominant social relations and mores but to confront them.

For this reason, the whistling of the workers at the Mercedes plant could rather be taken to approximate to an articulation, if not exactly a voicing, ${ }^{26}$ of what James C. Scott called the 'hidden transcripts' that accompany and underlie asymmetrical social relations. In the South African case I examine here, resistant not-exactly-hidden transcripts are rendered dramatically audible as whistling, communicating powerfully precisely by eluding verbal specificity. Scott's theorisation of the ways in which the subaltern resist dominance is often contrasted with the Gramscian account of hegemony. Unlike Gramsci, Scott argues that the private quotidian behaviour of people in subaltern positions (which, in the cases he is primarily concerned with, tend to be the agrarian peasantry) shows not that they have consented to dominance, but rather that they sustain resistant countercultures 'offstage', outside the 'public transcripts' by which they apparently acquiesce to their subjection. Yet there are moments when this hidden transcript surfaces, with potentially revolutionary consequences ${ }^{27}$ Brought to bear in the case considered here, such a hidden transcript could be said simultaneously to surface in the shrill whistling at Mercedes that makes the message public, and to elude scrutiny due to its sonic rather than phonemic character. ${ }^{28}$

\section{Towards Epistemologies of Echo and Resonance}

In his speculative but stimulating account of the political economy of music, the French theorist Jacques Attali draws attention to the centrality of noise that sonically rivals the prevailing social order. ${ }^{29}$ For Attali, sound is implicated in the very distinctions that underpin and articulate the social, and noise serves as a metaphor for a transhistorical vanguardism that constitutes 'an anticipatory abstraction of the shape of things to come.' His book opens with a rhetorical provocation that entails an invitation: 'For twenty-five centuries, Western knowledge has tried to look upon the world. It has failed to understand that the world is not for the beholding. It is for hearing. It is not legible, but audible. ${ }^{30}$

Mowitt's most recent book of 2015, Sounds, develops this idea in particular directions, answering his own call (in his earlier book Percussion) to amplify the capacity

Mowitt, Sounds, 'Introduction', Squawking section III, paragraph 12 designates sounds like whistles, whispers and gasps as 'nonvocalized vocalizations (sounds that occur in or on speech but that lack phonemic value)' (references to page numbers in Sounds are to the Kindle version of the book).

27 James C. Scott, Domination and the Arts of Resistance: Hidden Transcripts (New Haven: Yale University Press, 1990).

28 I am indebted to Mowitt, Sounds, 'Introduction', Squawking section III, paragraph 13 for this distinction.

29 Jacques Attali, Noise: The Political Economy of Music, translated by Brian Massumi (Minneapolis and London: University of Minnesota Press, 1985). Tellingly, given my focus here, Attali ventures that ' $t$ the distinction between musician and nonmusician ... undoubtedly represents one of the very first divisions of labor, one of the very first social differentiations in the history of humanity, even predating the social hierarchy'.

Attali, Noise, 3 . 
of music to make demands on theory through 'obliging theory to sound themes other than those associated with its canonical profile. ${ }^{31}$ The observations I have made about one particular case of shrill whistling in this essay risk falling into precisely the modes of scholarship that Mowitt invokes sound to critique, where theory is applied to a practice (like shrill whistling) which is thereby illuminated, but where the role of theory remains, as he puts it, 'for external use only' - it is applied to an object that is assumed to have some sort of metatheoretical primacy. I concur with Mowitt about the promise of pursuing modes of inquiry in which sound in general (he refers specifically to music in the passage I am citing here) 'must be granted the authority to provoke theorizing - that is, to provoke a reading of theory that challenges its integrity, that obliges theory to submit to the same, often violent scrutiny that its detractors claim is visited on those practices to which it has been applied.32

Mowitt's project in Sounds is thus to elaborate modes of knowledge that are grounded in aural experience and might invite us to revisit some of the central concepts of critical theory and supplement their visual biases. One example in Mowitt's book is conceptualising the relationship of texts to their contexts in terms of echo rather than reflection. Taking up an essay of the mid-1970s by Machery titled 'The Problem of Reflection, Mowitt elaborates:

[R]eflection - modeled as it is on the model of specular repetition - gives expression to an epistemological axiom consistent with 'visualism'. Mind mirrors world, and the putative task of human endeavor is to perfect this mirroring ...

The echo would appear to operate in accord with a different epistemological axiom, one that interferes with mirroring by insisting on a foundational (thus antifoundational) distortion ... where the difference between the transmission of light and sound becomes paramount, the fact is that echo is structured by delay, by time. Moreover, the delay always marks a decay. Something is missing from the sound source, and as a consequence the 'mirroring' is more than simply reversed; it is systemically imperfect. ${ }^{33}$

This insight is particularly consequential for Mowitt for the ways in which it complicates the problem of contextualisation in the humanities. What would it entail, he challenges us to think, to account for the 'systemic imperfections' that characterise the relation between a text or practice (like shrill whistling), if it does not merely reflect the circumstances of its emergence but echoes them? ${ }^{34}$ As I see it, this would encourage mindfulness of the extent to which a filmic narrative such as Gush's - and indeed my analysis here - cannot merely reflect what is revealed in the historical sources but necessarily must account for what decays, even in the act of affording

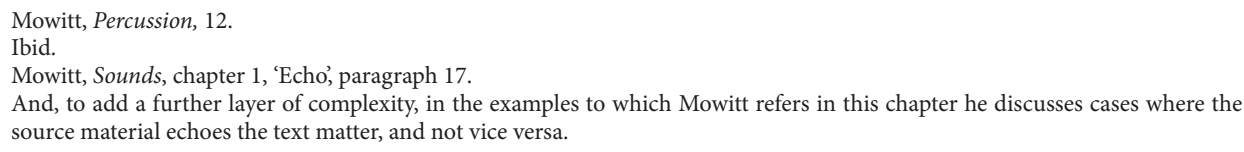


attention to the events that took place at the Mercedes plant in East London in 1990. ${ }^{35}$ The time lag between those events and the present renders it particularly appropriate to conceive of the relationship between a historical event and the work of historiography as an echo, as an attempt to hear a time departed over again. Such an epistemology also invites us to unpack the connotations of resonance; for how, in recognising patterns from the past in the present, we might sense correspondences that may not be explicable in terms of mechanical causality, but which stand in a kind of sympathetic - or unsympathetic - vibration with the present. Placing an artwork at the centre of analysis seems to help to foreground these interpretive dimensions of historical understanding that might be less clear in the customary recourse to the canonical archive.

\section{Conclusion}

With these considerations in mind, returning to my own project of considering a sonic phenomenon empirically as well as theoretically, I wish to close by offering some further brief conjectures on not only what it means for a work of art to be placed at the centre of a historical reading, but what it specifically means for a work of sound art to be placed at the centre of such an endeavour. There is a second performative aural image that stands out for me in Gush's film, and it concerns the moment of the car assembled for Madiba coming off the production line. In the film, this is relayed in a montage of recollections on the part of three interviewees:

Andile Ntsonkota:

We normally used to have a truck called 'Fred' to drive this vehicle...to put the vehicle into Fred from paint-shop to the assembly area.

Philip Groom:

But that car [Mandela's red Mercedes] didn't go with that. That car was literally carried, the body.

Mteteleni Tshete:

Né [So], you'll imagine when that car comes down. Jirre man! [God, man!] A group of workers were singing. Could not really believe, no one really told us the car was coming. Everybody was singing, the car was lifted high up. Philip Groom:

No, they put it on a trolley, but everybody was ... and singing and dancing all over and the guys on the other end were dancing ... waiting to receive this car.

Mteteleni Tshete:

We wanted to prove to everybody that we can do it on our own. We didn't need supervision. We know what to do. 
These slightly disjunctive recollections (whether or not the car 'came down' on a trolley or not, and when exactly) cohere in a suspension of the conventional automated process, and the transport of the body of the vehicle between the sections of the plant becomes animated by the affective transport of choral song. By two of the accounts, the body of the car is lifted by the workers, invoking two distinct, emotionally charged modes of public performance from 1980s South Africa: the carrying of sporting heroes on the shoulders of fans, and the carrying of the coffins of struggle heroes on the shoulders of mourners at mass funerals. Both of these contrasting images are, of course, implicitly associated with particular sonic accompaniments.

Whether presenting antagonistic whistling or celebratory song, Gush's film (which is of course framed by the rest of the installation) enlists the audience to imagine these ringing moments. Such impressions are amplified, in my view, by Gush not attempting to provide diegetic sound that approximates to these largely irretrievable historical performances. In the theatre of memory, sound is all the more evocative. ${ }^{36}$ And so not only the sonic assemblages but also the deliberate silences in Gush's film leave rich questions reverberating that invite reflection. How do the temporalities of history shared by particular constituencies - like cohorts of workers - register and shift from a sonic perspective? How do the social and the intensely personal affective dimensions of aural expression and memory inform one another? How are particular subjectivities - in this instance those of resistant labourers who for a moment become self-empowered agents of their own industry - established and contested in the modern social collective through shared sound practices? Might the social itself be aurally constituted, at least in part, as Attali boldly asserts? ${ }^{37}$ In cases such as the one that Gush thematises in this piece, which dimensions of labour history can be assembled with reference to its historical 'soundtrack'? And were one to attempt to do so, which particular challenges of conservation and restoration would pertain to recovering histories of sound in their face of their ephemerality?

I will not venture to offer answers to such questions here, not only because of considerations of space but precisely because I take the value of Gush's project to lie in the ways in which it serves as a multisensory prompt to further inquiry. What I will venture to offer is a closing reflection on how the foregrounding of performance in the constitution of social and public memory leads me to reconsider the assumption that sociality predates concrete enactment and that social actors are necessarily guided by a self-evident common script of shared values. I wonder whether the

36 With respect to the social nature of memory, Mowitt in Sounds takes up Benjamin's argument (in his famous 'Age of Mechanical Reproduction' essay) that 'as the capitalist mode of production came of age ... it began to redistribute the structural occasions for the production of critical consciousness' (chapter 2, 'Whistle', Sound Politics section II, paragraph 2). For Benjamin, memory plays a crucial part in the production of consciousness, for which he retrieves and elaborates Proust's distinction between voluntary and involuntary memory (chapter 2, 'Whistle', Sound Politics section II, paragraph 3 ). The latter is, by this account, unconscious, while the former, which Benjamin associates with 'the explosion of mnemotechnics (steam printing, photography, phonography, cinematography, etc.) in the nineteenth century - is deliberative, conscious as a matter of principle, but for precisely that reason voluntary memory is memory that contains no trace of the past whatsoever'. Benjamin insisted on 'the social forces registered in the discourse and practice of involuntary memory'; memory is thus 'structured by the factions warring over not just its contents but the form of its contents' (chapter 2, 'Whistle', Sound Politics section II, paragraph 5).

37 For a recent critical engagement with Attali's ideas within music studies, see David Novak's Japanoise: Music at the Edge of Circulation (Durham NC: Duke University Press, 2013), 230-1. 
performances of resistance at the Mercedes-Benz plant in East London in the late 1980 s and early 1990s reflect a culture of resistance that was shared by workers with common socioeconomic interests, or whether those performances might themselves have yielded and engendered forms of solidarity that co-constituted the workers as a collectivity?

Veit Erlmann has argued, drawing on an idea advanced by Johannes Fabian, that shifting focus 'from the informative to the performative' allows for a theory of knowledge production where knowledge does not depend on the transfer of somehow preexisting messages via signs, symbols or codes. ${ }^{38}$ In that case, sociality and cultural meaning are not merely represented in cultural practice, as if they could be conceived prior to acts of enunciation or realisation; rather, they are created as they are enacted in it. In the two moments on which I have focused in this essay, whether shrill whistling or celebratory song, performance sonically constitutes a defiant collectivity who refuse to isolate the workplace from the struggle beyond its walls while maintaining the formal routines of production, or alternatively, transforms that space and those very routines of production into a site of liberation.

By shifting the frameworks within which we consider cultures and social identities from nouns to verbs - from ostensibly stable things to things people do - performance invites us to ask whether and how cultural values are shared through their enactment. This leaves open what might be shared as a question, rather than assuming the salience or coherence of a predetermined 'culture' on the basis of assigning subject positions to social actors, a process which is always ideologically loaded in settings like South Africa. Among the conversations assembled around Gush's primarily visual artwork at the conference from which this essay emerges, thinking not only about but also with sound proved fruitful. I hope that the moves in this direction offered above will yield further calls and responses.

Veit Erlmann, Hearing Cultures: Essays on Sound, Listening, and Modernity (New York and Oxford: Berg, 2004), 19. Erlmann draws on a body of theory propounded in the field of performance studies as well as ethnographies of performance. For exemplary ethnographies of performance, particularly in African contexts, see Johannes Fabian's Power and Performance: Ethnographic Explorations through Proverbial Wisdom and Theatre in Shaba, Zaire (Madison WI: University of Wisconsin Press, 1990) and Corrine A. Kratz's Affecting Performance: Meaning, Movement and Experience in Okiek Women's Initiation (Washington DC: Smithsonian Institution Press, 1994). 